Bull. Mater. Sci., Vol. 4, No. 3, May 1982, pp. 283-288. (C) Printed in India.

\title{
Potential new solidification experiments in space environment
}

\author{
P K ROHATGI, $M$ R MADHAVA and $M$ K SURAPPA \\ Regional Research Laboratory, Trivandrum 695 019, India \\ MS received 4 Tebruary 1980; revised 10 January 1981
}

\begin{abstract}
The paper discusses the potential effects of space environment an solidification; reviews the previous solidification experiments in space and suggests newexperiments. The proposed experiments in space include (a) breakdown of planar interfaces in transparent systems, (b) thermal perturbations ahead of interfaces, (c) dendrite spacings, (d) fragmentation of dendrites and their transport, (e) solute concentration profiles in castings, (f) maximum undercoolings in alloy melts under containerless conditions; ultrafine structures produced on freezing of highly undercooled melts, (g) preparation of wires and ribbons from alloys; solidification in ultrathin films and (h) dendritic shrinkage.
\end{abstract}

Keywords. Space environment ; solidification ; planar interfaces ; thermal perturbations; dendrite spacing; dendrite shrinkage; ultrathin films.

\section{Introduction}

Solidification essentially involves the transformation from liquid to solid state accompanied by rearrangement of a.toms and release of latent heat. This transformation has been discussed in several books and papers (for example Chalmers 1964; Flemings 1974; Mukherjee 1979) and we shall deal only with those aspects which are relevant to subsequent discussion on the possible effects of space on solidification.

One of the problems is the nucleation of solid from bulk liquid. Once the solid has nucleated, then comes the problem of growth of these nuclei through additions of increasing number of atoms from liquid to the solid. On a microscopic scale, at each point of the solid-liquid interface, as the atoms are transferred from the liquid to the solid, latent heat is released. This heat is conducted away from the interface into the solid, or the liquid, or both to maintain the temperature of the interface at or below equilibrium temperature to allow for further growth on a microscopic scale.

When there is a difference in the composition between the solid that initially precipitates and the liquid, rejection of certain solute atoms occurs at the solidliquid interface. This solute has to move away from the interface down the concentration gradient by diffusion and/ar ky pracesses of fluid flow. In addition to the convection driven by momentum transfer, shrinkage and thermal gradients during solidification, fluid flow occurs due to concentration gradients present in 
the liquid, since the concentration gradients lead to density gradients. The convection velocity $v$ is related to the density gradients in the following manner

$$
v=f\left(\partial \rho_{L} / \partial x, g, \eta\right),
$$

where $g$ is the acceleration due to gravity and $\eta$ is the viscosity of the fluid.

Fluid flow during solidification can change the effective rate of heat transfer; it can fragment the already formed solid dendrites into pieces and transfer them to other parts of liquid to act as nuclei; the flow of solute-rich liquid can redissolve some of the already formed solid.

\section{Potential effects of space processing on solidification phenomena}

The low pressure of space can change the equilibrium ccnditions under which solid and liquid can coexist. When solidification is accompanied ty a contraction in volume, the freezing point of pure metals will be lowered; in alloy systems with partition ratio $(K)$ lower than unity, both the solidus and liquidus temperatures will also be lowered.

The possibility of nucleation resulting from statistical fluctuations and cavitation accompanying fluid flow will be much less in the space environment and this leads to higher undercooling. During the solidification of castings, due to the reduced fluid flow, the fragments already formed and transported into the remaining liquid will be considerably less. The growth phenomenon will also be influenced since the effective diffusion coefficients, fluid flow and thermal fluctuation will be different in space. These factors will influence the concentration gradients, perturbations at the interface and spacing between dendrites and eutectic lamellae.

The velocity generated due to the density differences [equation (1)] will be considerably lowered in the reduced gravity of space environment. This in turn will affect the heat transfer, shape of interface profile and temperature fluctuations at the interface. These could lead to considerably reduced banding during the growth of crystals.

Even after the aendrites are formed, the interdendritic fluid flow velocity $v$ is related to the pressure gradients and acceleration due to gravity $g$ according to Darcy's law:

$$
v=-\frac{c}{\mu f_{L}}\left(\nabla P+\rho_{L} g\right),
$$

where $c$ is a constant termed the permeability of the medium $P$ the pressure, $\mu$ the viscosity, $f_{L}$ the volume fraction of liquid and $\rho_{\mathbf{L}}$ the liquid density. The interdendritic flow velocity will again be considerably lowered in space due to low values of gravity and reduced pressure differences driving the flow.

\section{Observations of previous solidification experiments in space}

A very large number of experiments an solidification have been conducted in space under a variety of $g$ conditions and sample preparation techniques (Hasemeyer et al 1974; Malmejac and Walter 1979; Naumann 1979; Steg 1977). In this section we only mention the results of the more significant experiments which demonstrate an effect of space environment on solidification phenomena. 
Results of experiments performed in space on materials processing and solidification indicate that space environment leads to: (i) dendrites which are more regular and uniformly spaced, (ii) eutectio structures with uniform spacing, longer fibres and lesser faults, (iii) reduced banding in crystals.

\section{Potential new experiments in space on solidification}

\subsection{Observations of interface breakdown in transparent materials}

The exact mechanism of formation of cells and dendrites as a result of interface breakdown during solidification is still not very well understood. The constitutional supercooling theory proposed by Chalmers and co-workers (Rutter and Chalmers 1953; Tiller et al 1953) suggests that a planar interface breaks down when the supercooling ahead of it exceeds a certain critical value:

$$
\boldsymbol{G}_{L} / R \geqslant-m_{L} c_{0}(1-K) / K D_{L}
$$

where the notations have their usual meaning. Several experiments have been conducted on the ground including solidification of $\mathrm{Pb}-\mathrm{Sn}$ alloys (Walton et al 1955) and indium alloys with $\mathrm{Cd}, \mathrm{Tl}$ and $\mathrm{Pb}$ (Madhava 1977) and transparent organic compounds like $\mathrm{CBr}_{4}$ (Jackson and Hunt 1965). It will be interesting to measure the critical ratio of temperature gradients to the rate of growth at which planar interfaces become unstable in space, specially in transparent systems such as $\mathrm{CBr}_{4}$ for which ground data exists.

\subsection{Formation of dendrites}

In general, the spacing between cells or dendrites is considered to be related to the difiusion coefficients, the rate of growth and heat flow out of the melt. A proposed relationship (Rohatgi and Adams 1967) is as follows:

$$
L^{2}=\frac{8 \triangle C D}{\bar{c}(1-K)}\left(\frac{d \theta}{d f_{\mathrm{s}}}\right)
$$

Since it is observed that the effective diffusion caefficients $(D)$ in space can be markedly lower than the ground values (Ang 1978) it will be desirable to measure the change in the dendrite arm spacing $(L)$. The systems that could be studied include Ice- $\mathrm{NaCl}$ (Rohatgi et al 1969), $\mathrm{NH}_{4} \mathrm{Cl}$-water (Jackson et al 1966) and $\mathrm{Al}-4 \cdot 5 \% \mathrm{Cu}$ (Bower et al 1966) for which data on ground already exist. It will also be instructive to measu re the solute concentration profiles within the dendrites and amount and size of second phase particles for alloys such as $\mathrm{A} 1-4 \cdot 5 \% \mathrm{Cu}$.

\subsection{Experiments with highly supercooled melts}

With containerless solidification experiments in space it may be possible to obtain dimensionless undercoolings greater than unity resulting in ultrafine structures. These structures should be investigated in systems such as ice, nickel, tin, cobalt, germanium (Chalmers 1964), bismuth (Glicksman and Schaeffer 1968) and phosphorus (Glicksman and Schaeffer 1967) which have already been studied at $1 \mathrm{~g}$. 


\subsection{Production of wires, ribbons and sheets from melts}

One of the problems of spinning wires, ribbons and sheets from liquid metals on ground is the breakdown of fluid film due to forces of gravity which overcome the forces of surface tension. It will be desirable to ascertaia the maximum width of films of liquid metals and alloys which are stable in space; and try to produce wires and large sheets from the melts in space (possibly using a suitable solar furnace for melting) and study the solidification mechanisms in ultrathin films. Initial work can begin with iron and aluminium.

\subsection{Dendrite remelting experiments}

The formation of equiaxed crystals has been reported to be due to the separation of necked crystals from the mould walls in the initial stages of solidification, before the formation of stable solid skin (Ohno 1971; Ohno and Motegi 1975). This mechanism is frequently masked in the ground experiments due to the fluid flow induced dendrite fragmentation. Therefore it will be necessary to perform experiments with both non-metallic as well as metallic systems in space where fluid flow is reduced. These experiments could be designed to create controlled convection at the beginning of solidification and observe the formation of necked crystals and equiaxed structure at the centre of castings.

\subsection{Measurement of thermal fluctuations ahead of solidifying interface}

Temperature fluctuations ahead of solidifying interfaces (resulting from natural convection) have been measured on ground as a function of temperature gradient for example in tin (Utech and Fleming; 1967). It will be useful to compare the magnitudes and wavelengtbs of these fluctuations with the fluctuations measured during solidification of tin in space.

\subsection{Growth of eutectics}

Initial work, on the measurement of interfaca profiles and structures produced in space can begin with the transparent eutectic systems investigated by Hunt and Jackson (1966) for which ground data in agreement with the theory of eutectic solidification are already available.

\subsection{Measurement of interdendritic shrinkage in castings}

Fluid flow accurs between dendrites in the solid-liquid region due to: (i) the presence of capillary forces, (ii) gravity and (iii) pressure differences. This flow fills the shrinkage cavities.

It is not possible to separate the contributions to fluid flow from capillary forces in ground experiments since this flow is masked by the gravity and pressure-driven fluid flow. Experiments should be conducted with suitable alloys (e.g., Al-4.5\% $\mathrm{Cu}$ ) in space to measure the interdendritic shrinkage and to quantify the interdendritic flow at low gravity and low pressure conditions under different dendrite morphologies. 


\subsection{Growth rate as a function of undercooling}

It will be interesting to measure the growth rate of perfect ice crystals along $c$ direction, and of gallium and tin, as a function of undercooling in space and compare with the results of ground experiments (Hillig 1958).

\subsection{Solidification of castings}

Directional freezing of systems like $\mathrm{Al}-\mathrm{Cu}$ and $\mathrm{AlNiC}$ for which considerable ground experimental data exist (Bower et al 1966; Singh et al 1970) should be investigated in space to study columnar to equiaxed transition.

\subsection{Measurement of diffusion coefficients}

It will be desirable to measu re the diffusion coefficients of $\mathrm{Cu}$ in liquid $\mathrm{Al}$-metals with very different densities and atomic size-for which diffusion coefficients dendrite spacings, size and amount of second phase particles etc., have been measured on ground (Bower et al 1966; Singh et al 1970).

\subsection{Melting of solid cylinders}

Otto and Lacy observed (Steg 1977) that cylinders of ice transformed to spheres during the process of melting in space environment. Similar experiments with metals like $\mathrm{Al}, \mathrm{Fe}$, In, where the surface tension and gravity effects are quite different from those for ice, should be performed.

\subsection{Fluid flow in systems which expand on freezing}

Suitable experiments should be performed in space to study the fluid and solidification shrinkage during the solidification of materials such as gallium and cast iron which expand upon soliaification.

\subsection{Inverse segregation patterns in castings}

It will be useful to study the change in the pattern of inverse segregation due to space castings of long freezing range alloys such as $\mathrm{Al}-4.5 \% \mathrm{Cu}$ for which considerable ground data already exist (Bower et al 1966; Singh et al 1970).

\section{References}

Ang C Y 1978 J. Met. p. 28

Bower T F, Brody H D and Flemings M C 1966 Trans. AIME 236624

Chalmers B 1964 Principles of solidification (New York: John Wiley)

Flemings M C 1974 Solidification processing (New York : McGraw-Hill)

Glicksman M E and Schaeffer R J 1967 J. Cryst. Growth. 67297

Glicksman M E and Schaeffer R J 1968 The solidification of metals (London : Iron and Steel) Inst.) Publ. No. 110 , p. 43

Hasemayer E A, Lavoy C V and Lacy L L 1974 Skylab results, Proc. III Space Symp. (Alabama : NASA Marshall Space Flight Centre) 1457

Hillig W B 1958 Growth and perfection of crystals ed. R H Doremus (New York: John Wiley p. 350 
Hunt J D and Jackson K A 1966 Trans. AIME 236843

Jackson K A and Hunt J D 1965 Acta Metall. 131212

Madhava M R 1977 An ultrasonic study of phase transformations in indium Alloys, Ph.D. Thesis, University of Bath, England

Malmejac Y and Walter H U 1979 Materials science research with sounding rockets (Paris: European Space Agency)

Mukherjee P C 1979 Fundamentals of metal casting tectnology (New Delhi and Oxford: IBH)

Naumann R J 1979 Early space experiments in materials processing (Alabama : NASA Marshall Space Flight Centre)

Ohno A 1971 Trans. Iron Steel Inst. Japan 1118

Ohno A and. Motegi T 1975 AFS Cast Metals Res. J. p. 45

Rohatgi P K and Adams C M Ir 1967 Trans. AIME 2391737

Rohatgi P K and Adams C M Jr 1969 Trans. AIME 245267

Rutter J W and Chalmers B 1953 Can. J. Phys. 3115

Singh S N, Bardes B P and Flemings M C 1970 Met. Trans. 11383

Steg L (ed.) 1977 Materials science in space with applications to space processing (New York : Am. Inst. Aeronaut. Astronaut.)

Tiller W A, Jackson K A, Rutter J W and Chalmers B 1953 Acta Metall. 1428

Utech H P and Flemings M C 1967 Crystal growth ed. H S Peiser (New York : Pergamon)

Walton D, Tiller W A, Rutter J W and Winegard W C 1955 Trans. AIME 2031023 